\title{
The Survey on Scientific Chinese Use at the Universities in Xinjiang
}

\author{
Xiaoling Ma \\ Preparatory Education College, Xinjiang University, Urumqi, 830008, China
}

\begin{abstract}
Keywords: Science, Bilingualism, Use.
\end{abstract}
\begin{abstract}
Taking the sociolinguistics, education, psychology as guide, with the sample research, classroom watch and subject interview, the article analyses the scientific Chinese use at the universities in Xinjiang, in order to suggest for the national and Chinese teaching integration. The article thinks that we must try to the popularization of bilingual teaching model I , development of bilingual balance ability, upright of bilingual teaching manner, effective transformation of bilingual codes, correct form of study strategies.
\end{abstract}

\section{Introduction}

In 1992, the autonomous region people's government proposed to carry out experimental teaching of bilingual instruction in minority subjects such as number, rationale, and discipline of ethnic minorities, and the bilingual education of minority subjects began. After more than 10 years of development, since 2004, universities such as Xinjiang University, Xinjiang Normal University and Xinjiang Medical University have begun to experiment with Chinese teaching in minority sciences, engineering and most of arts major, that is, all courses use Chinese as the teaching language, Chinese teaching materials as a textbook, the purpose of the experiment is the integration of civil and teaching, that is, the students adopt a unified teaching objectives and teaching standards. After 3-4 years of experimentation, as of 2008, the minority universities and engineering majors in major universities and colleges in Xinjiang officially decided to teach in Chinese and use Chinese teaching materials. In the teaching of minority nationalities in colleges and universities, the use of Chinese as a teaching language is not only helpful for teachers to impart knowledge and students' learning abilities? What difficulties and suggestions do students have for Chinese teaching and Chinese teaching materials? What is the difference between bilingual and monophonic monographs? With these questions, we investigated the ethnic minority teachers and students of science major in Xinjiang universities from two aspects: the use of Chinese in classroom teaching and the use of Chinese in order to observe the practical application of Chinese teaching in physics teaching and feedback.

The survey was conducted in the form of a sample survey conducted by Xinjiang Normal University and investigated by teachers and students of ethnic minorities specialized in physics of the School of Physics. Samples taken randomly, the sample number of teachers 15, 30 students. Including 8 male teachers, 7 female teachers, 11 young teachers aged 25-45, 4 middle-aged teachers aged 45-60, 2 junior titles, 6 intermediate titles, 7 senior titles, and male students 1812 students of Uyghur, 23 students of Uyghur, 7 students of Kazak students, 8 urban students, 22 rural students, physical scores 30-50 26, 50-60 points 4 people, MHK score 300- 400 points 20 people, 200-300 points 10 people. Taking into account the teachers and students in the questionnaire there is a certain scruple, in order to more truly reflect the voices of teachers and students, we also conducted related interviews and classroom observation. The following is a combination of interview and observation, the analysis of the findings:

\section{Influence of a Bilingual Teaching Mode}

Teaching model usually refers to a representative and standardized teaching paradigm. It is a plan or paradigm that forms a course, selects materials, and guides teaching activities. Therefore, the curriculum is also a category of teaching mode, the framework or mode of curriculum is the narrow teaching mode. Bilingual teaching in primary and secondary schools in our region, there are usually 
three kinds of curriculum model: mode 1 is the science course and the Chinese course with Chinese teaching, other subjects taught in civilian language; mode 2 is in addition to civilian languages, music and other courses, the content related to national music and traditional culture can be taught in the native language. The other courses are taught in Chinese. The third mode is all courses taught in Chinese. At present, Pattern 1 is basically adopted in all four southern prefectures in which the population of ethnic minorities is relatively concentrated and is recognized by the vast majority of ethnic minority cadres and intellectuals. In the northern and eastern regions, especially in large and medium-sized cities and small towns, more use of mode 3. However, no matter what kind of mode, require the use of Chinese as a classroom language to teach the number of science and chemistry courses. In view of this, it has been more than 20 years since physics lessons taught in Chinese have been taught.

However, $80 \%$ of the students in the survey admitted that only $20 \%$ of the students "teach physics in middle schools and teachers use mother-tongue teaching" and "teachers use bilingual or Chinese teaching". Due to the artificial modification of bilingual teaching mode in most secondary schools, there is a wide range of incommensu rate phenomena in teachers' teaching of Chinese using physics after students enter universities, especially at the end of matriculation. The incommensurate rate is as high as $\mathbf{4 6 . 7 \%}$. This high degree of maladjustment is anxiety in fact, which greatly inhibits the students' interest in physics. The outstanding performance is that self-regulated learning is not active (46.7\%), and there is not much enthusiasm for participating in class interaction (43.3\%). The thought of overcoming difficulties and learning profession is not strong (53.3\%), and there is not enough attention (50\%) in the development of this subject. Psychology that: for more complex learning, such as for very unfamiliar knowledge learning or need to rely on random changes, more flexible knowledge of learning, high anxiety is inhibited. For example, from the students' physical college entrance examination scores and the entrance into the professional study of physical examination results comparison, the degree of improvement in more than 30 points accounted for $10 \%$, 20 points or more accounted for $33.3 \%, 10$ points or more accounted for $56.75 \%$. Can be seen, after a year of tutorial and preview, due to not adapt to college physics (including basic physics) teaching mode, the effect of learning less than expected, did not meet expectations.

\section{The Impact of Bilingual Differences}

Bilingual balance refers to the ability of bilingual operators to master both languages and to use the same two languages. This is a perfect or ideal bilingual phenomenon. In other words, bilinguals have the same language ability in A and B languages. Conversely, bilinguals are called non-bilingual if their abilities are not synchronized in A and B languages. Osgood argues that Bilingual Balancers (ie, bilingualism) use two separate speech systems. One uses language A to understand and answer the same information conveyed in language $\mathrm{A}$. On the one hand, using language $\mathrm{B}$ to understand the same language $\mathrm{B}$ the information and give the answer. Non-bilingual balancers (ie, coordinated bilingualism) have only one dominant language system, language $\mathrm{A}$, which he understands and answers when he receives the information of language $A$. When he receives the language $B$, he wants to translate it into A for understanding and A to answer, and then translated into B to express it.

According to the survey, 46.7\% attained MHK Level 3, 46.7\% for Level 3 and 6.6\% for Level 2, and none of them reached Level 4 of MHK. MHK four indicators described as: You can use Chinese to work in professional communication; You can speak in Chinese, write professional articles in Chinese; The basic can use Chinese to think. It is clear that bilingual learners who reach MHK Level 4 begin to approach the bilingual balance. As most of the students surveyed are non-bilingual, up to $90 \%$ of students said that "the biggest difficulty in thinking in Chinese is understanding and expressing in physical classrooms"; $96.7 \%$ of students think that "in physics classes, Uighur $63.3 \%$ of the students discussed the teaching content in Uighur and their classmates. The above reflection is essentially the translation of thinking in leading everything, that is, to understand and respond in mother tongue, and then expressed in Chinese. Most of the young teachers in the survey (73.3\% of the total) used "Chinese and Uyghur for lectures" due to their good bilingual abilities. They also agreed 
that "Chinese lectures are more effective" and "prepare lessons - teaching - coaching "In the direct use of Chinese expression. Some older teachers (about 26.7\%), due to the imbalanced development of their bilingual ability, agreed that "the teaching effect of the mother tongue was more pronounced" and that the teaching was conducted in the form of translation.

\section{The Impact of the Bilingual Transcoding}

Translation is to transform the language that carries the information, the information carried by one language is expressed in another language, and the purpose of social communication is achieved through the conversion of the two languages. The translation process is reflected in bilingual people is the transfer of bilingual code, that is, from one language to another language. In general, there are two factors that affect the transfer of bilingual code: social environment and psychological factors. The former refers to the occasion of speaking, the topic and the interpersonal relationship; the latter refers to the speaker familiar with the semantic coding system. Due to the fact that the mixed classes of civil and military colleges and universities in Xinjiang are not common at present, most of them are ethnic minority teachers. Therefore, ethnic minority students usually use Uyghur language to communicate with each other. Especially in the bilingual system of learners, it is more convenient to transfer code in the mother tongue because of the native language proficiency and the lack of proficiency in Chinese.

Taking the current textbook as an example, although the textbook is written in Chinese, up to $96.7 \%$ of the students who choose "to understand and think in the Uyghur language are in the physical class, " 63.3\% of the students who discuss the content of teaching in Uyghur language and classmates 86.7\% of the students favor "writing physics textbooks in both Chinese and mother tongue", 70\% of the students are teachers who teach textbooks in their mother tongue, and $83.3 \%$ of them are students who master the best of both native and Chinese. In fact, the general tendency of students is that in the physical classroom, the choice of codes is mainly mother tongue, supplemented by Chinese. Since the main language code-based, which means that the Chinese code to be converted into mother-tongue code.

$80 \%$ of students think that "understanding and expressing Chinese terminology" is the biggest difficulty. In fact, it is the question of translatability of terminology. According to linguist statistics, professional vocabulary in bilingual teaching accounts for only $20 \%$, of which $60 \%$ are primary words and $40 \%$ are advanced words. Bilingual teaching of physics vocabulary can be taught in two ways: direct method and translation method. Direct method is to use Chinese to explain the Chinese description; translation method is to use the student's mother tongue translation, the student's mother tongue description. The current middle school physics teaching to use more translation method, its implementation is based on the professional vocabulary is more primary, and has standardized, popular forms of translation and science, a solid cognitive foundation. However, most of the college physics vocabulary is senior, and the form of translation is not uniform, the scope of access is small, the cognitive basis is weak, so its translatability value is not high, and its economic significance is not significant. Therefore, the direct method is more suitable for college physics teaching vocabulary.

\section{Influence of Language Attitudes}

Language attitude refers to the use of language group or individual value of a language evaluation and behavioral tendencies, the formation of a variety of social factors is the result of the combined effect. A nation's linguistic conception determines their knowledge of the language in use, their knowledge of the existence and development of the language, their attitude toward the native language, their attitudes toward the use of the dual language and the language, and their attitudes toward the language used. It can be said that the bilingualism of bilingual learners determines their attitude towards the use of dual-language and use of the occasion, and even to some extent, its bilingual level. 
Admittedly, with the further development of bilingual teaching, ethnic minority students in Xinjiang are enthusiastic about learning and using Chinese. By the end of 2016, there were 2.1261 million students of bilingual minority classes (including Han nationality) receiving pre-school and primary and secondary education (including vocational high schools), accounting for $80.23 \%$ of the total number of students in the district. However, because of propaganda and cognitive bias, many ethnic minority students still regard bilingual teaching simply as Chinese class, that is, they narrowly understand the role of Chinese in bilingual teaching. Bilingual teaching in a broad sense refers to the education of people in ethnic minority schools in both languages. Narrow-sense bilingual teaching refers to the use of Chinese in minority schools to teach mathematics, physics, chemistry, history, geography and other disciplines. In other words, bilingual teaching refers not only to teaching Chinese as a minority, but also to teaching other courses that use Chinese as a classroom language. However, as can be seen from the sampling questionnaire, as many as $63.3 \%$ of students still narrowly understand bilingual teaching as a language course or a Chinese course. For example, $63.3 \%$ of the students choose "teachers to use their mother tongue to teach materials", $20 \%$ to "teachers teach in the mother tongue from the beginning to the end", and $70 \%$ to "the key part and the difficult part to teach in the mother tongue". For the sake of the unified teaching, $43.3 \%$ of the students who chose to take the physical examination in Chinese should take $23.3 \%$ of the students, and only $23.3 \%$ of the students are in favor of the mixed class of the civil and Chinese, according to the requirements of the Chinese students60 \%. Nevertheless, up to $93.3 \%$ of students still accepted that "the level of Chinese language helps to understand the physics curriculum. "

In contrast, interviewed teachers have a profound understanding of physics bilingual teaching. For example, 73.3\% of teachers choose "Chinese and Uyghur for teaching", 80\% of teachers have "Chinese teaching effect is more obvious", and $46.7 \%$ of teachers teach "Chinese from beginning to end. " In addition, $60 \%$ of teachers are "in favor of the mixed class of civil and military education, according to the requirements of the Chinese students, " and $86.7 \%$ of the teachers who "should attend the physical examination with Chinese. "

\section{The Impact of Learning Strategies}

Bloom believes that education goals that students learning outcomes should include three areas of cognitive learning, emotional learning and motor skills learning. Affective learning areas include learning strategies and attitude motivations, the former learns how to learn, the latter is behavior and motivation. Learning strategies are students' skills to regulate and govern their internal organization of attention, memory, and thinking as they learn, and are ways in which learners can "manage" their own learning processes. In short, learners form their own observation problems, analyze problems and solve problems. As far as bilingual teaching is concerned, especially Chinese teaching, learning strategy and attitude motivation are one of the core teaching contents and are also an important part of language comprehensive utilization ability. For example, the minority Chinese compulsory education in our district mainly uses Chinese teaching of "nine-year compulsory education for full-time primary school Chinese teaching outline (trial)" issued by the former State Education Commission, which explicitly proposed to make students: cultivate the beauty of love; exercise observation, thinking, imagination, memory ability; develop good will character and study habits.

In the long-term bilingual teaching activities, teachers and students pay more attention to language knowledge, language skills and cultural awareness, ignoring the formation of learning strategies and attitude motivation, resulting in less self-regulated learning ability and less correct motivation to learn. However, these shortcomings are very conspicuous in the physics bilingual teaching, which directly leads to the insignificant teaching effect and the low learning interest. For example, only $13.3 \%$ of the students "read the Chinese extracurricular books in extracurricular time", and $10 \%$ of the students "often exchange experience in physical learning with Chinese students or ask questions about them", and $40 \%$ of students "often take the initiative to do Chinese notes and homework. " In contrast, 93.3\% of teachers "often use Chinese reference materials during lesson preparation", 86.7\% of teachers write lesson plans in Chinese, $80 \%$ of teachers write relevant teaching and research 
articles in Chinese, and 53.3\% Of teachers "both in Chinese, but also write research papers in their own language."

These are some of the observations we made about the use of Chinese in science teaching in colleges and universities in Xinjiang. To a certain extent, this reflects the current status of bilingual teaching. In order to improve the effectiveness of science bilingual education for minority nationalities in Xinjiang universities and realize the teaching goal of integration between the civilizations and Chinese nationalities, we must promote the bilingual teaching model 1, the construction of bilingual balance ability, the correctness of bilingual teaching attitude, the effective conversion of bilingual codes and learning the correct formation of strategy work hard.

\section{Acknowledgements}

Regional Education Department of Bilingual Education Key Project "Autonomous primary and secondary schools bilingual teaching quality monitoring system and evaluation criteria"( project number: SY20152019) ; Key Research Base of Humanities and Social Sciences in Ordinary Colleges and Universities "Xinjiang Minority Bilingual Education Research Center" - Investigation and Research on the Cultivation Effect of Xinjiang Minority Students in Mainland Universities and Colleges ( Project Number: 040414C03) .

\section{References}

[1]. Morey. Educational Psychology [M]. Guangzhou: Guangdong Higher Education Press, 2002: 454.

[2]. Osgood. The measurement of meaning [M]. Urbana: The University of Illinois Press, 1957: 142.

[3]. Mackay, Sigurd, Introduction to Bilingual Education [M]. Yan Zheng, Liu Xiufeng, translated. Beijing: Guangming Daily Press, 1989: 8.

[4]. Department of Ethnic Education, Ministry of Education Outline of Chinese Language Proficiency Test for Minorities [M] .Beijing: Beijing Language and Culture University Press, 2002: 3.

[5]. Wang Dechun. Introduction to Linguistics [M]. Shanghai: Shanghai Foreign Language Education Press, 2000: 320.

[6]. Wang Binhua. Bilingual Education and Bilingual Teaching [M]. Shanghai: Shanghai Education Press, 2003: 244.

[7]. Shen Xiaolong. Community culture and language variation: social linguistics vertical and horizontal talk [M]. Changchun: Jilin Education Press, 1991: 229.

[8]. Dai Qing Xia. Language and ethnic [M] Beijing: Central University for Nationalities Press, 1994: 95.

[9]. Li Ruzhong.Ten comments on bilingual education [M] Urumqi: Xinjiang People's Publishing House, 2012: 55.

[10]. Bloom. Human Characteristics and School Learning [M]. New York: McGraw-Hill, 1976: 162. 